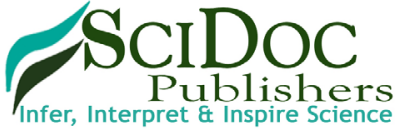

International Journal of Food Science, Nutrition and Dietetics (IJFS)

ISSN:2326-3350

\title{
Effect of Synthesized ZnO Nanoparticles As Antioxidant on Cotton Seed Oil and Its Blend with Palm Olean
}

Research Article

Salama LI ${ }^{1 *}$, Mohamed B. Atta ${ }^{1}$, Nehal A. Ali ${ }^{2}$

${ }^{1}$ Faculty of Agriculture, Department Of Food Sciences and Technology, Tanta University, Egypt.

${ }^{2}$ Department of Engineering Physics and Mathematics, Faculty of Engineering, Tanta University, Egypt.

Abstract

Nanoparticles of zinc oxide ( $\mathrm{ZnO} \mathrm{NPs}$ ) using the precursor citrate was formed as a single phase one stage with the size of $25 \mathrm{~nm}$. ZnO NPs was used at different concentrations $\left(1,2,5 \mathrm{mML}^{-1}\right)$ in some edible oils [cotton seed oil and its blend with palm Olean in the ratio of $1: 1(\mathrm{v} / \mathrm{v})$ during heat stress as antioxidant. Some of the chemical characteristics of the oil were estimated as an indicator of deterioration as a result of oxidation during thermal stress within two hours. The results revealed that chemical characteristics (e.g. PV, p-AV and Totox value) of oils that contained $1 \mathrm{mML}^{-1} \mathrm{ZnO}$ NPs were not affected significantly compared to those free from $\mathrm{ZnO}$ NPs during heat stress. These results suggested that $\mathrm{ZnO}$ NPs has a potential power to control the oxidation process during heat stress of edible oil and could be used as synthetic antioxidant agent. More studies concerning the solubility of $\mathrm{ZnO}$ NPs and its nutritional effect on the animal lab are needed.

Keywords: Antioxidant; Edible Oil; Heat Stability; Heat Stress; Oxidation; ZnO NPs.

\section{Introduction}

Fried foods spread extensively all over the world as basic meals at fast food outlets. During frying, chemical and physical changes are take place leading to fast deterioration of oils [1]. Most of these changes include oxidation of double bonds in fatty acids [peroxides], hydrolysis of triglycerides producing free fatty acids, pyrolysis and cyclization which effects on the reflective index and color of oil [2]. Deterioration of oil is occurring as a result of either hydrolytic rancidity or oxidative rancidity. Oxidative rancidity refers to reaction of unsaturated fatty acids in lipid with air oxygen to form peroxides which is called induction period [first phase of oil oxidation]. With the continuation of oxidation, peroxides decompose producing mixtures of aldehydes, ketones, acids and other volatile products [secondary phase of oil oxidation]. These products are responsible for "rancid" odors and off-flavors. Also, cis/trans isomerization and polymerization; due to repetition of heating; are increased the melting point and viscosity of the oil [3]. Not only the oil oxidation is altering the nutritive value and flavor of fatty foods, but also toxic substances could be created which considered as health hazard and decreases consumer's acceptability [4]. The oxidation rate can accelerate by high tempera- ture, presence of water, free fatty acids and catalysts such as heavy metals [5]. Also, oxidation will reduce the storage life and keeping quality of fatty foods. Therefore, antioxidants are used to prevent lipid oxidation and delaying the creation of oxidation products in food system. Free radical scavenging such as Butylated hydroxyanisole [BHA], butylated hydroxytoluene [BHT], propyl gallate [PG], tert-butylhydroquinone [TBHQ] and tocopherols are the most synthetic antioxidants used at the commercial scale to control autoxidation process in fatty foods [6].

With the emergence of nanotechnology, the important properties of nanostructured materials have started motivation among scientists to explore the possibilities of using them in different applications. The search for effective bioactive agents has focused on the development of nanostructures of metals like silver, copper, zinc and gold [6]. $\mathrm{ZnO}$ is considered one of the best metal oxides that can be used at a Nano-scale level and currently listed as generally recognized as safe [GRAS] by the U.S. Food and Drug Administration [21CFR182.8991] [FAD 2011]. Also, ZONPs at different concentrations $[0.03 \%, 0.07 \%$ and $0.5 \%]$ prolong the shelf-life of strawberry fruit in cold storage after harvesting from 0 to 18 days and decreased the microbial load during fruit stor-

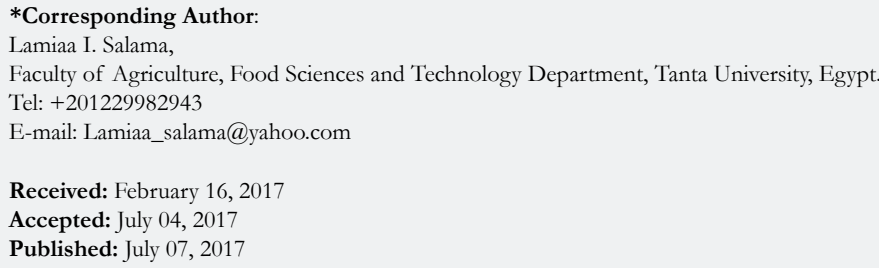

Copyright: Salama $\mathbf{L I}^{\circ}$ 2017. This is an open-access article distributed under the terms of the Creative Commons Attribution License, which permits unrestricted use, distribution and reproduction in any medium, provided the original author and source are credited. 
age, delayed weight loss, retained fruit firmness and maintained anthocyanin, vitamin $\mathrm{C}$, phenol content and antioxidant activity at higher concentration than those of untreated fruit [7]. Toxicological studies showed that $\mathrm{ZnO}$ NPs could be inhibited lipid peroxidation in cell membrane and internal organs of rats at a concentration of $600 \mathrm{mg} / \mathrm{ml}$ proving that $\mathrm{ZnO} N$ Ps may reduce risks to living tissues in both plants and animals [8]. Notice, $\mathrm{ZnO}$ NPs has been used for a long time as an active ingredient for dermatological applications in creams, lotions and ointments, depending on its ability to stop the growth of bacteria [9]. Furthermore, it could be used in some foods as antimicrobial. For example, 5 and $8 \mathrm{mM}$ suspensions of $\mathrm{ZnO}$ NPs containing citric acid could be effective to stop growth of Listeria monocytogenes, Escherichia coli, Staphylococcus aureus and Bacillus cereus in mango juice [10]. ZnO NPs have been contained environmentally safe mineral elements essential to humans when administered in small amount [11].

This work was designed to prepare zinc oxide nanoparticles [ $\mathrm{ZnO}$ NPs] using the precursor citrate and study its characterization via [the complete name] XRD, [the complete name] TEM and Infrared spectroscopic [IR] methods. The effect of ZnO NPs at different concentrations on some chemical characteristics of cotton seed oil and its blend with palm Olean in the ratio of 1:1 $[\mathrm{v} / \mathrm{v}]$ compared to commercial antioxidants [TBHQ] during thermal stress was also studied.

\section{Material and Methods}

Fresh refined, free from synthetic antioxidant, cotton and palm Olean oils as well as TBHQ were kindly supplied from Tanta Oil and Soap Company, Tanta city, Al Gharbia Governorate, Egypt. Zinc nitrate and $\mathrm{p}$-anisidine were purchased from Sigma. All the rest of chemicals used were analytical grade.

\section{Preparation and characterization of $\mathrm{ZnO}$ NPs}

Nanocrystalline ZO was prepared by the citrate precursor method according to Duan X, et al., (2005) [12]. Aqueous solutions of Zinc nitrate and citric acid were prepared separate. After that, the mixed solution was dehydrated at $105^{\circ} \mathrm{C}$ till self-combustion reaction was started within the gel and converted into ash-like powder. The coarse powder was milled, sintered at $650^{\circ} \mathrm{C}$ with a heating rate of $5^{\circ} \mathrm{C} / \mathrm{min}$ for 2 hours and left to cool at room temperature. The phase identification of the sintered powder was characterized using XRD with X-Ray diffractometer, Philips X'Pert system with $\mathrm{Cu}-\mathrm{K} \alpha$ radiation $[\lambda=0.154056 \mathrm{~nm}]$. The crystallite size was estimated using Scherrer formula [13] as follows:

$\mathrm{D}=0.9 \lambda / B \cos \theta$

Where 0.9 is Scherrer's constant, $\lambda$ is the wavelength of $\mathrm{X}$-rays, $\theta$ is the Bragg diffraction angle, and $\beta$ is the full width at halfmaximum [FWHM] of the diffraction peak corresponding to plane $|101|$ located at $36^{\circ}$.

Microstructure and morphology of the powder were characterized by the transmission electron microscope TEM JJEOL, JEM-1400 Electron Microscope] and Fourier transform infrared spectroscopy [FTIR- spectroscopy] [BRUKER Model: Tensor 27] using $\mathrm{KBr}$ as sample medium to confirm phase formation.

\section{Determination of Heat Stability of Oil}

About $250 \mathrm{ml}$ of oil samples were placed in $500-\mathrm{ml}$ conical flasks mixed with $\mathrm{ZnO}$ NPs at different concentrations [1 $1 \mathrm{mM}, 2 \mathrm{mM}$ and $5 \mathrm{mM}$ ] along $80 \mathrm{mg}$ TBHQ/kg oil as standard commercial antioxidants were heated with occasionally stirring at $150 \mathrm{rpm}$ and $100^{\circ} \mathrm{C}$ for different periods [0, 90180 and $270 \mathrm{~min}$. Fresh refined oil sample free from TBHQ and $\mathrm{ZnO}$ NPs, was performed parallel as a control. Samples were withdrawn periodically and subjected to chemical analysis to monitor the oxidation process during heating stress.

\section{Chemical Analysis}

Peroxide value [PV] by iodometric technique[method no 965.33] and p-anisidine value [AnV] [Cd18-90] as described by AOCS [14] of oil samples were determined. The Totox value [TV] was calculated according to Stauffer [15] as follows:

Totox value $[T V]=2 P V+p-A V$

\section{Rancimat Method}

The ability of the oil bearing thermal oxidation was also measured using Schaal oven A 679 Rancimat [Metrohm, Herisan, Switzerland] according to Läubli and Bruttel [16]. About $5 \mathrm{~g}$ of oil was loaded into the reaction vessel cylinder. The air supply was maintained at $20 \mathrm{ml} / \mathrm{min}$ and the heating temperature was kept at $110^{\circ} \mathrm{C}$ throughout the experiment. Three different samples along control sample were conducted in one batch.

\section{Results and Discussion}

\section{Characterization of prepared ZO NPs}

$\boldsymbol{X R D}$ : Figure. 1 represents the X-ray diffraction pattern of ZONPs-powder. A definite line broadening of the XRD peaks indicates that the prepared material consists of particles in nano range. Seven major diffraction peaks were seen in Figure. 1 at 31.4, $34.2,36.2,47.4,56.3,62.4$ and 68.5 regions which can be assigned to diffraction from [100], [002], [101], [102], [110], [103] and [112] planes, respectively. These patterns are compared with those of the standard [JCPDF] cards. Single-phase hexagonal quartzite phase of ZnO NPs structure reveals well-defined diffraction lines and absence of any other phases. The average particle size of the sample was found to be $35 \mathrm{~nm}$ which is derived from the FWHM of more intense peak corresponding to 101 plane located at $36.2^{\circ}$ using Scherrer's formula.

\section{Fourier Transform Infrared Spectroscopy [FTIR spectros- copy]}

The FTIR spectra of ZnO NPs are helpful in expecting the position of the ions forming the crystal lattice through their vibrational modes. The FTIR spectrum of $\mathrm{ZnO}$ NPs was recorded from 200 to $3000 \mathrm{~cm}^{-1}$. As shown in Figure. 2, the following bands were observed: a band at $2924 \mathrm{~cm}^{-1}$ corresponding to stretching vibration of $\mathrm{CH} 3$; bands at 2924 and $2854 \mathrm{~cm}^{-1}$ corresponding to antisymmetric and symmetric stretching of C-H [17]; a band at 1505 $\mathrm{cm}^{-1}$ corresponding to $-\mathrm{C} \mathrm{H} 2$ deformation and $\mathrm{Zn}-\mathrm{O}$ stretching; and a band at $1044 \mathrm{~cm}^{-1}$ corresponding to $\mathrm{C}-\mathrm{O}$ stretching peak 
Figure 1. Represents the X-ray Diffraction Pattern of ZnO Nanopowder.

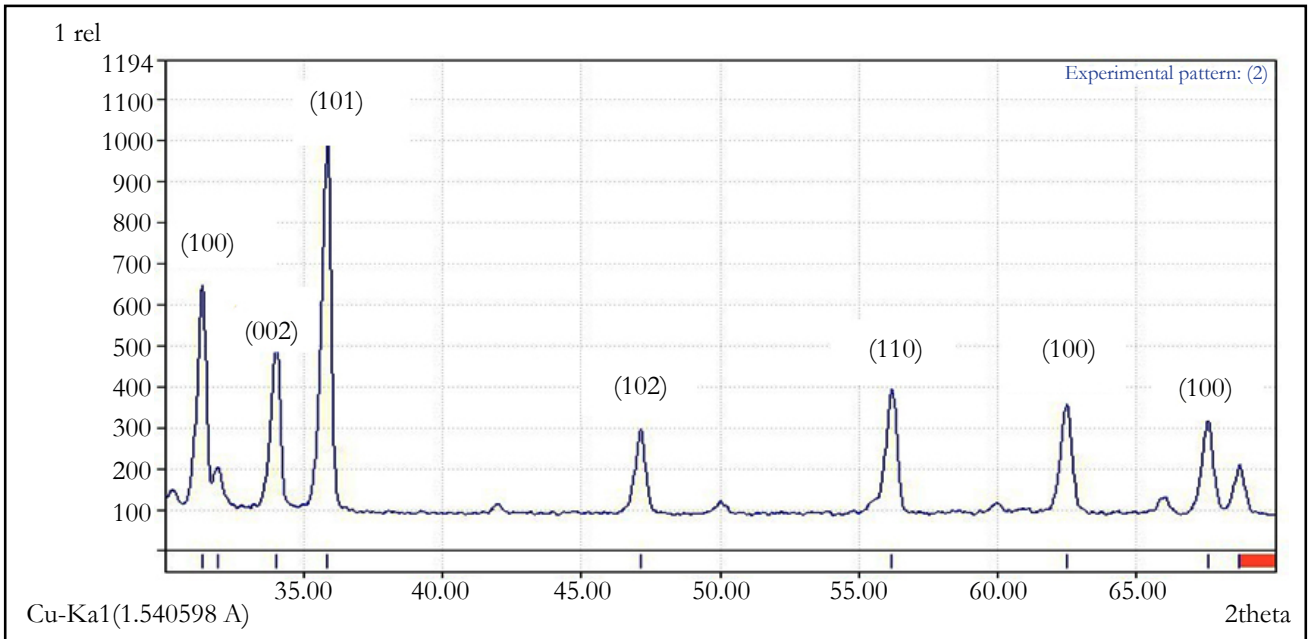

Figure 2. The FTIR Spectrum of $\mathrm{ZnO}$ nanoparticles.

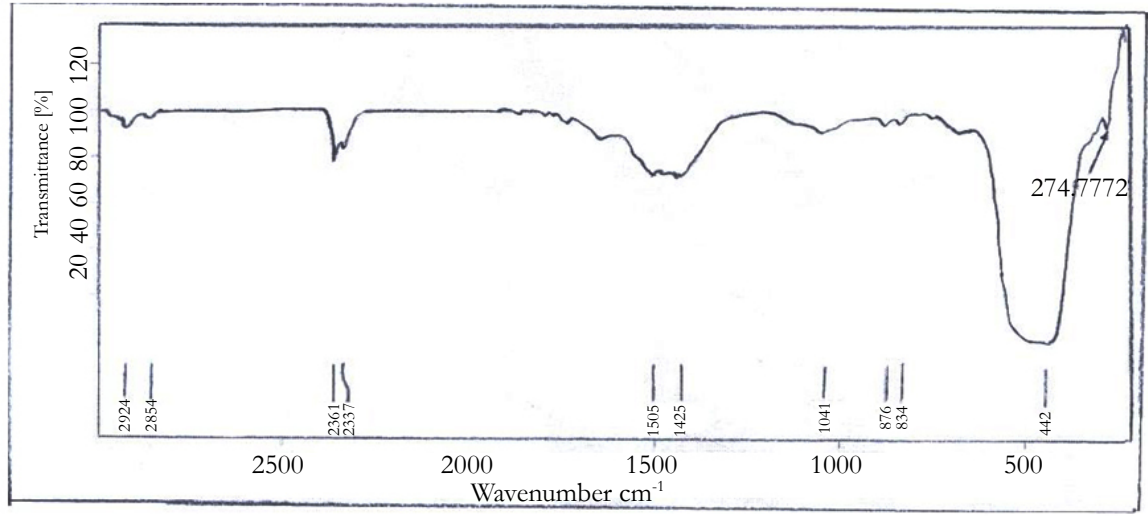

[18], and a band at $834 \mathrm{~cm}^{-1}$ corresponding to $\mathrm{C}-\mathrm{H}$ bending aromatic $\mathrm{CH}$ out-of-plane deformation. Parthasarathi and Thilagavathi [19] reported similar FTIR spectra observed of zinc oxide nanoparticles in their investigation.

\section{TEM Images}

It is clear from Figure 3. that TEM images of the ZnO NPs are not exactly circular, and their average size is about $40-50 \mathrm{~nm}$. This value is coinciding to that be calculated from x-ray data, using Scherrer formula.

\section{Determination of Antioxidant (Capacity of $\mathrm{ZnO} N P s$ in oil)}

Peroxide value (PV): The PV is normally used as an index for oil oxidative rancidity. Where, PV increases with the progress of oxidation the double bond in the fatty acids in oil during the induction period. It is clear from Table 1 that PV significantly decreases due to blend cotton oil with palm Olean in the ratio of $1: 1(\mathrm{v} / \mathrm{v})$. The PV of cotton seed oil is 1.50 which decreases to 1.33 for the blend oil. In other words, addition of palm Olean to cotton seed oil decreases PV by $11.33 \%$. This result is in agreement with those reported by Tiwari et al., [20] who stated that mixing oils increases the thermal stability of the oil. Also, the oxidative stability of the oil decreases with extends time of heating. Where the PV of fresh control cotton seed oil is $[1.50 \mathrm{meqO} / \mathrm{kg}$ oil $]$ gradually increases by extended the time of heating stress to reach 12.02 after 270 min. The addition of TBHQ or ZnO NPs to oil increases the oxidative stability. Where PV of cotton seed oil contains TBHQ or $1 \mathrm{mM} \mathrm{ZnO} \mathrm{NPs} \mathrm{after} 270 \mathrm{~min}$ heating at $100^{\circ}$ Care 8.23 and $5.56 \mathrm{meq} \mathrm{O} / \mathrm{Kg}$ oil, respectively. Also, the results display that the addition of $1 \mathrm{mM} \mathrm{ZnO} \mathrm{NPs} \mathrm{seems} \mathrm{to} \mathrm{be} \mathrm{the} \mathrm{superior} \mathrm{concentra-}$ tion due to the significantly decrease of PV [5.56mequ $\mathrm{O}_{2} / \mathrm{Kg}$ oil] after $270 \mathrm{~min}$ of heating. That is result could be due to their capability of forming excitonic pair $\left[\mathrm{e}^{-}, \mathrm{h}^{+}\right]$serve as a reactive oxygen species (ROS) scavenger]. The same trend is observed for blend oils, where addition of $1 \mathrm{mM} \mathrm{ZnO}$ NPs causes a significant decrement in the PV and increases the heat stability of the oil.

Anisidine Value (AnV): The AnV is a measure of alpha-beta unsaturated aldehydes or measures high molecular weight saturated and unsaturated carbonyl compounds in tri-acylglycerols of fats and oil [21]. Anisidine value is defined as 100 times of contribution of the extinction in $100 \mathrm{ml}$ solvent and anisidine reagents. As shown in Table 1 heating treatment increases the AnV for most samples after $270 \mathrm{~min}$. The $\mathrm{AnV}$ increases in both cotton seed oil and its blend free from antioxidants (TBHQ or ZnO NPs) to reach 44.4 and 43.1 after $270 \mathrm{~min}$ heating at $100^{\circ} \mathrm{C}$, respectively. The AnV of oils increase to a lesser extent for up to 39.62 and 38.58 in cotton seed oil and its blend containing $1 \mathrm{mM} \mathrm{ZnO}$ PNs after $270 \mathrm{~min}$ heating at $100^{\circ} \mathrm{C}$ comparing with 35.30 and 34.60 for oil containing TBHQ, respectively. Where AnV of oils contains TBHQ or ZO NPs are significantly lower than that of control sample during the heating stress. It is clear that, as the oil contains TBHQ or ZO NPs; AnV increases in lower rate during the heating stress that of control sample. However, $\mathrm{ZnO}$ NPs 
shows an excellent result in decreasing AnV. Whereas, adding 1 mM.L $L^{-1}$ of $\mathrm{ZnO}$ NPs to oil sample provides a decrease in $\mathrm{AnV}$ up to 35.30 and 34.60 in cotton seed oil and its blend, respectively. These results are in agreement with those reported by [22] who pointed out that adding of TBHQ to sunflower oil was effective in reducing $\mathrm{AnV}$ due to para hydroxyl group which made phenol more easily to donate hydrogen atoms to active free radicals to interrupt the chain reaction of antioxidant. While [23] mentioned that $\mathrm{OH}^{-}$in the NPs suspensions was much higher than ones in the bulk particles suspensions.

Totox Value: $\mathrm{PV}$ and $\mathrm{AnV}$ values reflect the oxidation level at early and later stages of oxidation reaction. Therefore, Totox value measures both hydro peroxides and their breakdown products which provide a better estimation of the progressive oxidative deterioration of fats and oils [15]. The data of Table 2 illustrates that Totox value significantly decreases with the addition of $1 \mathrm{mM} . \mathrm{L}^{-1}$ ZnO NP's in oil samples. Where, the lowest value is recorded by cotton seed oil (43.00) and its blend (37.20) after $270 \mathrm{~min}$ of heating at $100^{\circ} \mathrm{C}$. The corresponding values for oil samples containing TBHQ are 51.8 and 48.5, respectively. Although, there is no data on the inhibitory effect of ZnO NP's against lipid oxidation in oil during heating. This effect was assessed in this study in parallel with convective heating under comparable temperatures. On this topic, there is controversy regarding free radical formation when oils are subjected to heat treatments [24-26] and with the same direction they revealed that even a short period of microwave heating accelerates the formation of some undesirable and harmful compounds (e.g. oxidation products, transformed pigments) due to interactions between electromagnetic field with the chemical constituents of oil.

\section{Conclusion}

In conclusion, $\mathrm{ZnO}$ nanoparticles ( $\mathrm{ZnO}$ NP's) were prepared using citrate precursor method. The XRD, IR analysis, and TEM images clearly indicate the formation of highly pure $\mathrm{ZnO}$ nanoparticles. The performance of synthesized ZnO NP's to control the oxidation process of cotton seed oil and its blend during heat stress was tested by different measure parameters and their excellent effect was demonstrated. More studies are need to conduct investigation of the effect of stable suspension of ZnO NP's on vegetable oils and its toxicological experiments.

Figure 3. The TEM Images of $\mathrm{ZnO}$ Nanoparticles.
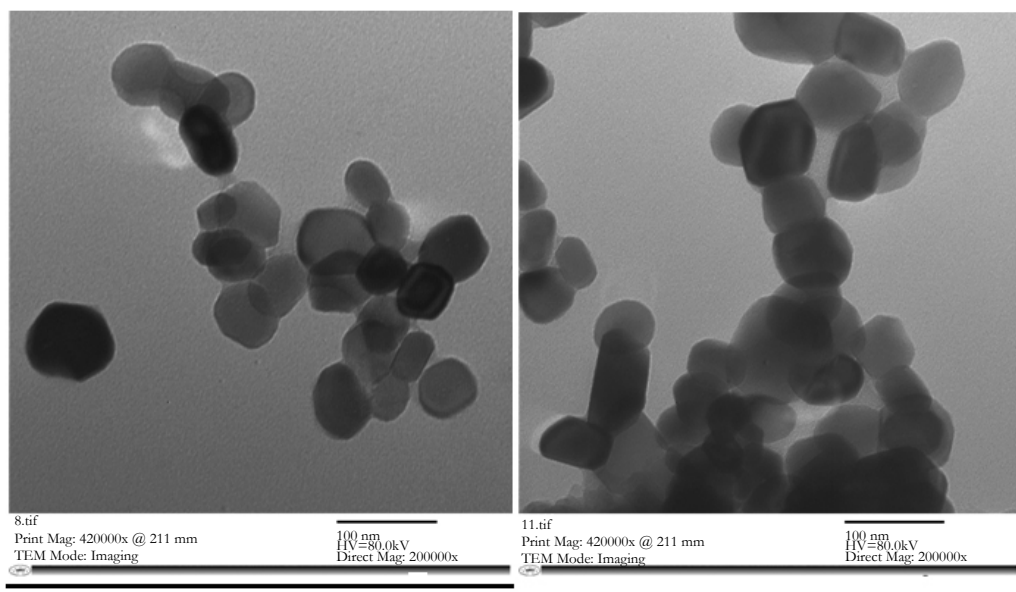

Table 1. $p$-Anisidine value [mg malondialdehyde/kg oil] and Peroxide value [meq O/Kg oil] of oil samples as affected by $\mathrm{ZnO}$ nanoparticles at different concentrations as antioxidant during heating stress.

\begin{tabular}{|c|c|c|c|c|c|c|c|c|c|c|}
\hline \multicolumn{11}{|c|}{ Peroxide value [meq $\mathrm{O} / \mathrm{Kg}$ oil] } \\
\hline \multirow{2}{*}{ Treatments } & \multicolumn{5}{|c|}{ Cotton seed oil } & \multicolumn{5}{|c|}{ Blend oil } \\
\hline & Control & TBHQ & $1 \mathrm{mM} . \mathrm{L}^{-1}$ & $2 \mathrm{mM} . \mathrm{L}^{-1}$ & $5 \mathrm{mM} . \mathrm{L}^{-1}$ & Control & TBHQ & $1 \mathrm{mM} . \mathrm{L}^{-1}$ & $2 \mathrm{mM} \cdot \mathrm{L}^{-1}$ & $5 \mathrm{mM} \cdot \mathrm{L}^{-1}$ \\
\hline $0 \min$ & $1.50 \pm 0.15$ & $1.50 \pm 0.15$ & $1.50 \pm 0.15$ & $1.50 \pm 0.15$ & $1.50 \pm 0.15$ & $1.33 \pm 0.02$ & $1.33 \pm 0.02$ & $1.33 \pm 0.02$ & $1.33 \pm 0.02$ & $1.33 \pm 0.02$ \\
\hline $90 \mathrm{~min}$ & $5.21 \pm 0.13$ & $4.46 \pm 0.18$ & $3.02 \pm 0.21$ & $3.78 \pm 0.22$ & $5.43 \pm 0.11$ & $5.69 \pm 0.13$ & $4.55 \pm 0.18$ & $2.73 \pm 0.21$ & $3.45 \pm 0.77$ & $4.49 \pm 0.11$ \\
\hline $180 \min$ & $9.21 \pm 0.24$ & $5.67 \pm 0.13$ & $4.93 \pm 0.19$ & $5.63 \pm 0.33$ & $8.57 \pm 0.17$ & $7.83 \pm 0.24$ & $5.28 \pm 0.13$ & $4.17 \pm 0.19$ & $5.14 \pm 0.33$ & $7.62 \pm 0.17$ \\
\hline $270 \mathrm{~min}$ & $12.02 \pm 0.38$ & $8.23 \pm 0.25$ & $5.56 \pm 0.32$ & $7.23 \pm 0.22$ & $9.95 \pm 0.22$ & $9.80 \pm 0.38$ & $6.97 \pm 0.25$ & $4.81 \pm 0.32$ & $6.85 \pm 0.22$ & $8.64 \pm 0.27$ \\
\hline \multicolumn{6}{|c|}{ LSD $=0.0611$ between treatments } & \multicolumn{4}{|c|}{ LSD $=0.1473$ between treatments } & \\
\hline \multicolumn{6}{|c|}{$\mathrm{F}=83.33^{* * *}$ between Time and treatments } & \multicolumn{4}{|c|}{$\mathrm{F}=76.78^{* * *}$ between time and treatments } & \\
\hline \multicolumn{11}{|c|}{$p$-Anisidin value [mg malondialdehyde/kg oil] } \\
\hline $0 \mathrm{~min}$ & $6.33 \pm 0.00$ & $6.33 \pm 0.00$ & $6.33 \pm 0.00$ & $6.33 \pm 0.00$ & $6.33 \pm 0.00$ & $5.92 \pm 0.00$ & $5.92 \pm 0.00$ & $5.92 \pm 0.00$ & $5.92 \pm 0.00$ & $5.92 \pm 0.00$ \\
\hline $90 \mathrm{~min}$ & $29.10 \pm 0.57$ & $24.30 \pm 0.59$ & $24.00 \pm 0.52$ & $19.50 \pm 1.66$ & $18.30 \pm 0.31$ & $28.70 \pm 0.57$ & $20.90 \pm 1.18$ & $19.30 \pm 0.52$ & $18.90 \pm 1.66$ & $18.00 \pm 0.31$ \\
\hline $180 \mathrm{~min}$ & $37.50 \pm 1.36$ & $35.00 \pm 1.28$ & $29.20 \pm 0.88$ & $25.10 \pm 1.1$ & $23.70 \pm 1.29$ & $33.80 \pm 1.36$ & $32.60 \pm 1.28$ & $25.80 \pm 0.88$ & $24.90 \pm 1.10$ & $23.10 \pm 1.29$ \\
\hline $270 \mathrm{~min}$ & $44.40 \pm 1.13$ & $39.62 \pm 0.74$ & $35.30 \pm 0.41$ & $32.20 \pm 1.62$ & $31.90 \pm 1.21$ & $43.10 \pm 1.13$ & $38.58 \pm 0.74$ & $34.60 \pm 0.46$ & $29.80 \pm 1.62$ & $27.60 \pm 1.21$ \\
\hline \multicolumn{6}{|c|}{$\mathrm{LSD}=0.6513$ between treatments } & \multicolumn{3}{|c|}{ LSD $=0.7989$ between treatments } & & \\
\hline & & $=38.13^{* * *}$ bet & veen time and & reatments & & $\mathrm{F}=29$. & $5^{* * *}$ between & me and treatm & & \\
\hline
\end{tabular}


Table 2. TOTOX value of oil samples as affected by $\mathrm{ZnO}$ nanoparticles at different concentrations as antioxidant during heating stress.

\begin{tabular}{|c|c|c|c|c|c|c|c|c|c|c|}
\hline \multirow{2}{*}{ Treatments } & \multicolumn{5}{|c|}{ Cotton seed oil } & \multicolumn{5}{|c|}{ Blend oil } \\
\hline & Control & TBHQ & $1 \mathrm{mM} . \mathrm{L}^{-1}$ & 2 mM.L ${ }^{-1}$ & 5 mM.L ${ }^{-1}$ & Control & TBHQ & $1{\mathrm{mM} . \mathrm{L}^{-1}}^{-1}$ & $2 \mathrm{mM} \mathrm{L}^{-1}$ & $5 \mathrm{mM} \mathrm{L}^{-1}$ \\
\hline $0 \min$ & $9.30 \pm 0.00$ & $9.30 \pm 0.00$ & $9.30 \pm 0.00$ & $9.30 \pm 0.00$ & $9.30 \pm 0.00$ & $8.60 \pm 0.00$ & $8.60 \pm 0.00$ & $8.60 \pm 0.00$ & $8.60 \pm 0.00$ & $8.60 \pm 0.00$ \\
\hline $90 \mathrm{~min}$ & $40.90 \pm 1.03$ & $32.90 \pm 0.88$ & $24.30 \pm 0.47$ & $27.10 \pm 0.72$ & $35.20 \pm 1.33$ & $40.10 \pm 1.03$ & $28.40 \pm 0.88$ & $23.50 \pm 0.47$ & $25.80 \pm 0.72$ & $29.90 \pm 1.33$ \\
\hline $180 \mathrm{~min}$ & $55.90 \pm 1.87$ & $40.50 \pm 0.67$ & $33.60 \pm 0.98$ & $36.40 \pm 0.59$ & $52.10 \pm 2.40$ & $49.50 \pm 1.87$ & $36.40 \pm 0.67$ & $31.40 \pm 1.01$ & $35.20 \pm 0.59$ & $47.80 \pm 1.00$ \\
\hline $270 \mathrm{~min}$ & $68.40 \pm 2.10$ & $51.80 \pm 1.04$ & $43.00 \pm 1.33$ & $46.70 \pm 0.32$ & $59.50 \pm 2.04$ & $62.70 \pm 2.10$ & $48.50 \pm 1.04$ & $37.20 \pm 1.33$ & $43.50 \pm 0.32$ & $55.90 \pm 2.03$ \\
\hline \multicolumn{11}{|c|}{ LSD $=0.7454$ between treatments } \\
\hline \multicolumn{6}{|c|}{$\mathrm{F}=85.90^{* * *}$ between time and treatments } & \multicolumn{4}{|c|}{$\mathrm{F}=47.27 * * *$ between time and treatments } & \\
\hline
\end{tabular}

\section{References}

[1]. Dabarganes C, Márquez-Ruiz G, Velasco G (2000) Interactions between fat and food during deep-frying. Eur J Lipid Sci Technol. 102(8-9): 521- 528.

[2]. Sahin S, Sumnu SG (2009) Advances in deep-fat frying of foods. Tylor and Francis group. Contemporary food Engineering. CRC Press.

[3]. Labuza T, Dugan P Jr L (1971) Kinetics of lipid oxidation in foods. C R C Critical Reviews in Food Technolgy. 2(3): 355-405.

[4]. Min DB, Lee HO (1999) Chemistry of lipid oxidation, Flavor Chemistry. Springer. 175-187.

[5]. Papadopoulos KN (2008) Food chemistry research developments. Nova Publishers, US

[6]. Shahidi F (2000) Antioxidants in food and food antioxidants. Nahrung. 44(3): 158-163

[7]. Sogvar OB, Saba MK, Emamifar K, Hallaj R (2016) Influence of nano- $\mathrm{ZnO}$ on microbial growth, bioactive content and postharvest quality of strawberries during storage. Innovative Food Sci Emerging Technol. 35: 168-176.

[8]. Singh BN, Rawat AKS, Khan W, Naqvi AH, Sinph BR (2014) Biosynthesis of Stable Antioxidant $\mathrm{ZnO}$ Nanoparticles by Pseudomonas aeruginosa Rhamnolipids. Plos One. 29(9): 1-12.

[9]. Sawai J, Igarashi H, Hashimoto A (1995) Evaluation of growth inhibitory effect of ceramics powder slurry on bacteria by conductance method. J of Chem Eng of Jap. 28(3): 288-293.

[10]. Firouzabadi FB, Noori M, Edalatbanah Y, Mirhosseini M (2014) ZnO nanoparticle suspensions containing citric acid as antimicrobial to control Listeria monocytogenes, Escherichia coli, Staphylococcus aureus and Bacillus cereus in mango juice. Food Cont. 42: 310-314.

[11]. Yousef JM, Daniel EN (2012) In vitro antibacterial activity and minimum inhibitory concentration of zinc oxide and nano-particle zinc oxide against pathogenic strains. J Health Sci. 2(4): 38-42.

[12]. Duan X, Yuan D, Sun Z, Luan C, Pan D, et al., (2005) Preparation of CO ${ }^{2+-}$ doped $\mathrm{ZnAl}_{2} \mathrm{O}_{4}$ nanoparticles by citrate sol-gel method. J alloys compounds. 386(1): 311-314.

[13]. Cullity B (1967) Elements of X-Ray Diffraction. (3rd Edn), Addison-Wesley, Reading, Mass, USA.
[14]. AOCS (2003) AOCS Official Method Cd 18-90. In Official Methods and Recommended Practices of the AOCS p-Anisidine, (6th Edn), 1-4.

[15]. Stauffer C (1996) In Fats \& Oils. Eagan Press, St. Paul, Minnesota. 40(5): $15-27$.

[16]. Läubli MW, Bruttel PA (1986) Determination of the oxidative stability of fats and oils: comparison between the active oxygen method (AOCS Cd 12-57) and the Rancimat method. J Am Oil Chem Soc. 63(6): 792-795.

[17]. Uchimyia M, Klasson KT, Wartelle LH, Lima IM (2011) Influence of soil properties on heavy metal sequestration by biochar amendment: 1 . Copper sorption isotherms and the release of cations. Chemosphere. 82(10): $1431-1437$.

[18]. Yuan W, Li B, Li L (2011) A green synthetic approach to graphene nanosheets for hydrogen adsorption. Applied Sur Sci. 257(23): 10183- 10187.

[19]. Parthasarathi V, Thilagavathi G (2011) Synthesis and characterization zinc oxide nano particles and its application on fabrics for microbe resistant defence clothing. Int J Pharm Pharm Sci. 3(4): 392-398.

[20]. Tiwari M, Tiwari K, Toliwal D (2014) Studies on thermal stability of palmsesame oil blends during deep fat frying. J Sci Indust Res. 73: 153-156.

[21]. Muik B, LendlB, Molina-Díaz A, Ayora-Cañada MJ (2005) Direct monitoring of lipid oxidation in edible oils by Fourier transform Raman spectroscopy. Chem physic lipids. 134(2): 173-182.

[22]. Akhtar H, Tariq I, Mahmood S, Hamid, S, Khanum R (2012) Effect of antioxidants on stability, nutritional values of refined sunflower oil during accelerated storage and thermal oxidation in frying. Bang J Sci indus Res. 47(2): 223-230

[23]. Xiong D, Fang T, Yu L, SimaX, Zhu W (2011) Effects of nano-scale TiO2, $\mathrm{ZnO}$ and their bulk counterparts on zebrafish: acute toxicity, oxidative stress and oxidative damage. Sci Total Environ. 409(8): 1444-1452.

[24]. Dostalova J, Hanzlik P, Reblova Z, Pokorny J (2005) Oxidative changes of vegetable oils during microwave heating. Czech $\mathrm{j}$ food sci. 23(6): 230.

[25]. ErkanN, Ayranci G, AyranciEA (2009) Kinetic study of oxidation development in sunflower oil under microwave heating: effect of natural antioxidants. Food res Int. 42(8): 1171-1177.

[26]. Megahed MG (2011) Effect of microwave heating of linseed oil on the formation of primary and secondary oxidation products. Agric Biol JN Am. 2(4): 673-679. 